\title{
Recent advances in diagnostic technologies in lung cancer
}

\author{
Hye Jung Park, Sang Hoon Lee, and Yoon Soo Chang
}

Department of Internal Medicine, Yonsei University College of

Medicine, Seoul, Korea

Received: January 30, 2020

Accepted: February 24, 2020

\section{Correspondence to}

\section{Yoon Soo Chang, M.D.}

Department of Internal

Medicine, Gangnam Severance

Hospital, Yonsei University

College of Medicine, 211

Eonju-ro, Gangnam-gu, Seoul

06273, Korea

Tel: +82-2-2019-3310

Fax: +82-2-3463-3882

E-mail:yschang@yuhs.ac

https://orcid.org/0000-0003-

$3340-4223$

This paper was contributed by The Korean Academy of Tuberculosis and Respiratory

Diseases.
The increase in lung cancer incidence of Korea has been dampened since 2000; however, increased human lifespan, interest in health care and the widespread implementation of health examinations have resulted in a considerable rise in detection of small lesions that need to be differentiated from lung cancer. Detection of lung cancer at an early stage rather than at a symptomatic advanced stage is also increasing, suggesting that there are increasing diagnostic demands for small peripheral lung lesions. The development of new molecular diagnostics, including next generation sequencing, companion diagnostics that accompany development of new anti-cancer drugs, and re-biopsy for application of new therapeutic modality accelerate the development of lung cancer diagnostics. In this review, we extensively describe the current available diagnostic tools in lung cancer.

Keywords: Companion diagnostics; Diagnostic tools; Incidence; Lung neoplasms

\section{INTRODUCTION}

According to the annual report of the Korean National Cancer Registration Statistics, the crude incidence of lung cancer per 100,000 people in 2016 was 50.4 , the 4 th highest among all cancers, following that of stomach, colon, and thyroid cancer. Lung cancer incidence appears to have continuously increased from 1997, with 52.7 crude incidence rate per 100,000 people in the year 2017; however, based on the age-adjusted ratio, it has remained steady since 2005 , peaking at 28.9 cases per 100,000 people (Fig. 1) [1]. This tendency is slightly different in male versus female population, with lung cancer incidence gradually decreasing for the former but still slowly increasing for the latter; this may be attributed to a decline in male smokers versus a rise in female smokers [2].

According to the 2018 report on the cases of death from the Statistics Korea, $26.5 \%$ of all deaths were cancer-related. Among all cancer-related deaths, the crude mortality rate due to lung cancer reached 34.8 cases per 100,000 people, and it was more than that from other cancer types (Fig. 2) [3,4]. Despite this, the 5-year relative survival rate for lung cancer has improved dramatically from $11.3 \%$ in the first survey period (1993 to 1995 ) to $28.2 \%$ (2012 to 2016). However, its survival-related prognosis is still the second worst following that of pancreatic cancer, with an $11.4 \% 5$-year survival rate (survey period: 2012 to 2016). These findings imply that majority of lung cancer patients are diagnosed at advanced stages which cannot be cured by surgery or other therapeutic modalities, but 

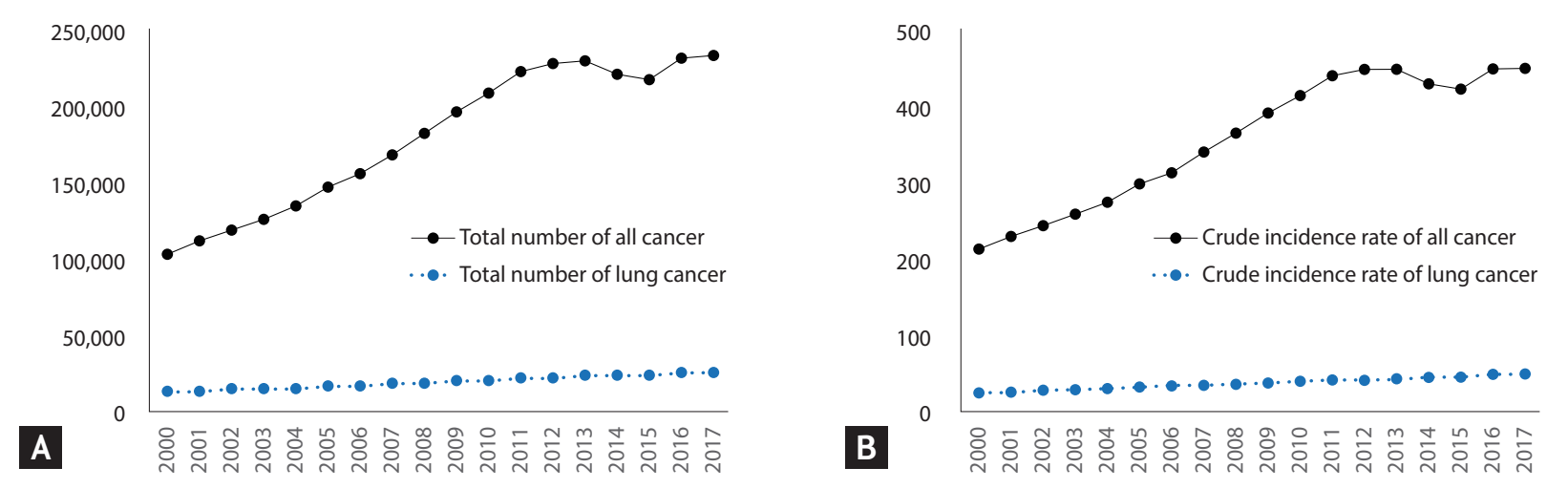

Figure 1. Annual incidence (A) of all cancer and lung cancer, and crude incidence rate per 100,000 population (B) of all cancer and lung cancer from 2000 to 2018 .
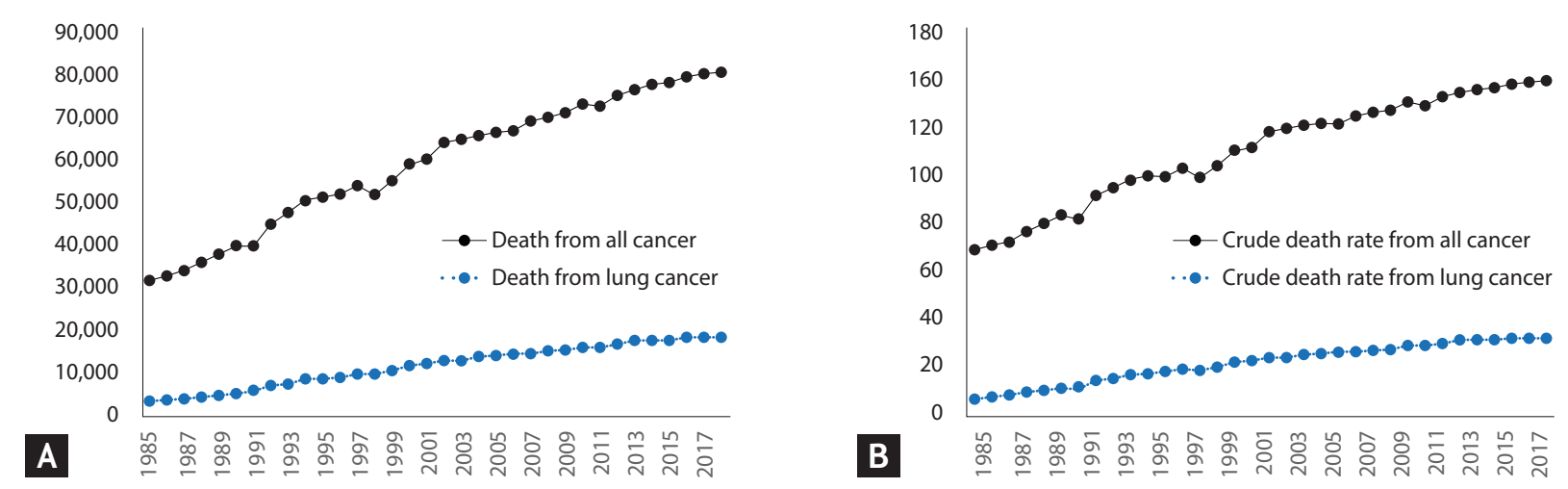

Figure 2. Annual death from (A) all cancer and lung cancer, and crude death rate per 100,000 population (B) of all cancer and lung cancer from 1985 to 2018 .

also indicate that there are great demands for improvement in the diagnosis and treatment. Recently, to standardize the diagnosis and treatment of lung cancer, the Korean Health Insurance Review and Assessment (HIRA) has developed indicators, applied evaluation guidelines and reported the results [5]. Moreover, in July 2019, Korean national lung cancer screening projects using lowdose chest computed tomography (CT) were launched for groups at high-risk for lung cancer. In this review, we discuss the diagnostic methods currently widely used for the diagnosis of lung cancer and describe their advantages and limitations.

\section{CLINICAL MANIFESTATIONS}

Symptoms of lung cancer can be classified into two categories: caused by the direct mass effect or invasion of the tumor or by paraneoplastic symptoms, which are systemic symptoms that are due to substances secreted by the tumor (Table 1). Symptoms owing to direct tumor invasion include cough, hemoptysis, wheezing, shortness of breath, obstructive pneumonia due to endobronchial growth of the primary tumor, and chest wall pain and shortness of breath due to restrictive dysfunction owing to peripheral growth of the tumor. Regional spread of tumor into the thorax can also cause symptoms depending on the involved organs. Invasion of the trachea by the tumor may result in dyspnea, invasion of the esophagus can cause dysphagia, involvement of the recurrent laryngeal nerve causes hoarseness, and diaphragmatic nerve involvement leads to respiratory distress related to diaphragm paralysis. In addition, invasion of the sympathetic nerves of the cervical spinal cord causes Horner's syndrome, characterized by enophthalmos, ptosis, miosis, and anhydrosis. Pancoast syndrome, caused by the 
Table 1. Symptoms from lung cancer

\begin{tabular}{|c|c|}
\hline & Comments \\
\hline \multicolumn{2}{|l|}{ Symptoms from direct tumor invasion } \\
\hline $\begin{array}{l}\text { Symptoms associated with central or endobronchial } \\
\text { growth of tumor }\end{array}$ & $\begin{array}{l}\text { Cough, hemoptysis, wheezing, shortness of breath, } \\
\text { obstructive pneumonia }\end{array}$ \\
\hline Symptoms associated with peripheral growth of tumor & Pleural and chest wall pain, dyspnea \\
\hline Horner's syndrome & $\begin{array}{l}\text { Sympathetic nerve paralysis; enopthalmos, ptosis, miosis } \\
\text { and anhydrosis }\end{array}$ \\
\hline Pancoast syndrome & $\begin{array}{l}\text { Involvement of the 8th cervical and 1-2nd thoracic nerve, } \\
\text { shoulder pain radiating ulnar distribution of the arm. }\end{array}$ \\
\hline Superior vena cava syndrome & Facial edema, right arm edema \\
\hline \multicolumn{2}{|c|}{ Symptoms associated with extra-thoracic metastatic disease } \\
\hline \multicolumn{2}{|l|}{ Paraneoplastic syndromes } \\
\hline Humoral hypercalcemia of malignancy & Ectopic secretion of PTHrP, Squamous cell lung cancer \\
\hline Syndrome of inappropriate antidiuretic hormone secretion & $\begin{array}{l}\text { Ectopic secretion of vasopression, common in the tumor with } \\
\text { neuroendocrine features, such as small cell lung cancer }\end{array}$ \\
\hline Ectopic Cushing's syndrome & $\begin{array}{l}\text { Ectopic ACTH production, common in neuroendocrine } \\
\text { tumor, such as small cell lung cancer }\end{array}$ \\
\hline Skeletal-connective tissue syndrome & Clubbing, hypertrophic primary osteoarthropathy, \\
\hline Neurologic-myopathic syndoromes & $\begin{array}{l}\text { Eator-Lambert syndrome, retinal blindness with SCLC, } \\
\text { peripheral neuropathies, subacute cerebellar degenration, } \\
\text { corical degernation, polymyositis }\end{array}$ \\
\hline
\end{tabular}

PTHrP, parathyroid hormone-related peptide; ACTH, adrenocorticotropic hormone.

invasion of the 8th cervical and 1st or 2nd thoracic nerve, presents as shoulder pain radiating along with the ulnar nerve distribution, and invasion of the superior vena cava leads to superior vena cava syndrome $[6,7]$. Lung cancer can metastasize to any organ in the body, which leads symptoms related to the metastatic lesion.

Paraneoplastic syndromes can occur in case of both benign and malignant tumors but are not correlated to the tumor mass or invasion, and are more commonly observed in tumors with a neuroendocrine origin. They occur in approximately $10 \%$ of lung cancer patients. Humoral hypercalcemia of malignancy, syndrome of inappropriate antidiuretic hormone secretion (SIADH), and ectopic Cushing's syndrome represent the most commonly reported symptoms. It is often challenging to distinguish symptoms caused by metastases of the carcinoma, and inappropriate diagnosis is associated with inappropriate treatment. Therefore, special attention is required when these particular symptoms are noted. Hypercalcemia is a life threatening complication often observed in lung squamous cell carcinoma and is caused by the ectopic secretion of the parathyroid hormone (PTH) or the PTH-related peptide inducing symptoms such as frequent urination, thirst, vomiting, nausea, abdominal pain, constipation, and, in severe cases, loss of consciousness. Hyponatremia in SIADH caused by the ectopic secretion of atrial natriuretic peptide can also occur frequently and requires careful evaluation as it may lead to loss of consciousness or death due to cerebral edema. Small cell lung cancer and bronchial carcinoid tumors may also lead to the development of Cushing's syndrome caused by an ectopic secretion of the adrenocorticotropic hormone and other hormones that can lead to neurologic symptoms owing to the formation of auto-antibodies [8]. In any case, if symptoms occur, it is likely that the disease is impossible to cure; thus, careful monitoring and accurate diagnoses must be carried out to improve prognosis in these patients. If suspected lung cancer lesions are found in high-risk patients or in previous examinations, it is necessary to accurately identify the nature of the lesion and conduct appropriate tests in a timely fashion, preferably prior to the occurrence of other symptoms. 


\section{IMAGING STUDIES}

Several imaging modalities can be used for the diagnosis and staging of patients with lung cancer. In real-world practice, combination of several imaging studies is needed to ensure accuracy of the diagnosis.

\section{Chest CT}

Chest CT is a fundamental imaging tool for the evaluation of lung cancer and is most commonly used as a noninvasive modality for the screening and staging of lung cancer. It is especially useful to define the size, location, and characterization of lung lesions, which are surrounded by air-filled lung tissue. Additionally, mediastinal and hilar lymphadenopathy, pleural effusion, metastasis in the liver, adrenal glands, bone, and other parts of the thoracic cavity can be assessed by chest CT. Since September 2019, low-dose chest CT (LDCT) has been adopted? for the screening of lung cancer in highrisk individuals in Korea. Screening with LDCT rather than conventional chest radiography is efficient to detect small lung nodules, leads to early intervention, and improves prognosis of lung cancer patients. The U.S. National Lung Cancer Screening Trial demonstrated that LDCT screening leads to a $20 \%$ reduction in lung cancer-associated mortality in high-risk populations compared to that seen with chest X-ray. Patients with positive results after LDCT need to be further evaluated using other diagnostic procedures [9].

\section{Positron emission tomography-CT}

Positron emission tomography (PET), using uptake of the radiolabeled glucose analogue [18F]-fluoro-2-doxyglucose by metabolically active cells, is a useful test for staging and thus deciding a treatment modality. It is also useful for the detection of extrathoracic disease. However, a false negative result may occur in cases of small lesions less than $1 \mathrm{~cm}$ in size and in tumors with low metabolic activity such as in case of carcinoid tumors or bronchioloalveolar cell carcinoma. In contrast, false positives can also occur when inflammatory conditions, such as pneumonia or granulomatous disease, are present. According to a report by Lee et al. [10], the false positive rates for PET-CT in the identification of mediastinal lymph node $(\mathrm{L} / \mathrm{N})$ metastasis in Korea can be as high as $87 \%$ when using endobronchial ultrasound-guided transbronchial needle aspiration (EBUS-TBNA) as a gold standard and significantly higher in patients older than 65 years with squamous cell carcinoma or pneumoconiosis. However, the same study reported that current or past history of tuberculosis did not significantly affect the false positive rate, unlike previous reports indicating that the usefulness of PET-CT decreased in areas with a high prevalence of tuberculosis [10].

\section{Brain magnetic resonance imaging}

Lung cancer, along with breast and malignant melanoma, are common causes of brain metastases, with lung cancer being the most common. Brain metastases can be detected as an early symptom in approximately $10 \%$ of diagnosed patients and associated with significant morbidity and limited survival [11]. The presence of symptomatic brain metastases is an important consideration in the selection of therapeutic agents and treatment modality. As the survival of lung cancer patients increases, improvement of drug permeability of the bloodbrain barrier has become an important consideration for pharmaceutical companies when developing anti-cancer drugs. HIRA guidelines recommend assessment of brain metastases for initial staging and preoperative evaluation of lung cancer [5]. However, with the recent increase in the early diagnosis of lung cancer, the need for brain magnetic resonance imaging (MRI) for staging tumors less than $2 \mathrm{~cm}$ in size has been questioned [12].

\section{Whole body bone scintigraphy}

Approximately $30 \%$ to $40 \%$ of non-small cell lung cancer (NSCLC) patients develop bone metastases that lead to poorer prognosis and worsen quality of life during the remaining life. Whole body bone scintigraphy (WBBS) is useful for the detection of bone metastases, when used in conjunction with other relevant clinical findings such as bone pain, elevated alkaline phosphatase, and hypercalcemia. It also has a high false positive rate due to trauma, inflammation and degenerative change of skeletal system and thus, the routine use of WBBS is not recommended by the National Comprehensive Cancer Network guidelines [13]. Moreover, implementation of WBBS for lung cancer is on the decline in Korea as the HIRA indicator does not include bone scans as imaging tools conducted for lung cancer bone metastasis [5]. 
Table 2. Advantages and disadvantages of commonly used biopsy procedures for lung cancer

\begin{tabular}{|c|c|c|}
\hline & Advantages & Disadvantages \\
\hline FBS & $\begin{array}{l}\text { High diagnostic yield for central and endobronchial } \\
\text { lesion }\end{array}$ & $\begin{array}{l}\text { Low diagnostic yield for non-endobronchial lesion } \\
\text { and peripheral lesion }\end{array}$ \\
\hline EBUS-TBNA & $\begin{array}{l}\text { Acquisition of real-time ultrasound images } \\
\text { Accessibility to central lung lesion and some L/N } \\
\text { (located in mediastinal, paratracheal, subcarinal, } \\
\text { hilar, and interlobar area) } \\
\text { Collection of cell and some lung tissue }\end{array}$ & $\begin{array}{l}\text { Limitation in evaluationg peripheral lung lesion and } \\
\text { other L/N }\end{array}$ \\
\hline EBUS-GS & $\begin{array}{l}\text { Acquisition of real-time ultrasound images } \\
\text { Improved accessibility to more peripheral lesion } \\
\text { Collection of cell and some lung tissue }\end{array}$ & $\begin{array}{l}\text { Requirement of professional training } \\
\text { Expensivenss }\end{array}$ \\
\hline $\begin{array}{l}\text { Navigation } \\
\text { bronchoscopy }\end{array}$ & $\begin{array}{l}\text { Acquisition of reconstructed and a virtual road map } \\
\text { to target } \\
\text { Improved accessibility to more peripheral lesion } \\
\text { Collection of cell and some lung tissue }\end{array}$ & $\begin{array}{l}\text { Requirement of navigation program } \\
\text { Expensiveness }\end{array}$ \\
\hline CT-NAB & $\begin{array}{l}\text { High diagnostic yield for peripheral lung lesion } \\
\text { (diameter }>2 \mathrm{~cm} \text { ) } \\
\text { Collection of cell and some lung tissue }\end{array}$ & $\begin{array}{l}\text { Need of patient's cooperation (Keep posture and } \\
\text { holding breath) }\end{array}$ \\
\hline Gun biopsy & $\begin{array}{l}\text { High diagnostic yield using core-biopsy needles } \\
\text { Collection of relatively sufficient lung tissue }\end{array}$ & $\begin{array}{l}\text { Need of patient's cooperation (Keep posture and } \\
\text { holding breath) } \\
\text { Relatively prevalent complication: pneumothorax } \\
\text { and pulmonary hemorrhage }\end{array}$ \\
\hline
\end{tabular}

FBS, fiberoptic bronchoscopy; EBUS-TBNA, endobronchial ultrasound-guided transbronchial needle aspiration; L/N, lymph node; EBUS-GS, endobronchial ultrasound using a guide; CT-NAB, needle aspiration biopsy with CT guidance.

\section{BIOPSY PROCEDURES}

Nowadays, biopsy has become indispensable not only for the diagnosis of lung cancer by confirming the presence of lung cancer cells but also for selection of appropriate treatment by molecular genetic testing. There are several tools for lung tissue biopsy that are currently used for diagnosis and staging of lung cancer. Selection of the diagnostic tools should take into account invasiveness and accuracy but also the location and characteristics of the lesion, the general condition of the patient, and the level of experience of the technician performing the examination (Table 2).

\section{Fiberoptic bronchoscopy}

The bronchial pathway to the target lesion and location where the sampling to be performed using forceps and brushes should be determined by careful review of the patient's anatomy before fiberoptic bronchoscopy (FBS) procedure. The diameter of commercial FBS is around $6 \mathrm{~mm}$ and lesions locating up to subsegmental bron- chus can be detected and biopsied using FBS. The diagnostic yield for FBS is low, ranging from $20 \%$ to $60 \%$ [14]. The size and location, and visibility of lesion are important factors that influence the diagnostic yield. Lung lesions less than $2 \mathrm{~cm}$ in diameter located in peripheral lung areas typically lead to low yields. In the case of endobronchial lesions that are located in central regions, three or more biopsies are recommended to achieve high diagnostic yields. Transbronchial biopsy, bronchial washing, and bronchial brushing can also improve the diagnostic yield for the lesions that are not directly visible by FBS. For peripheral lung lesions that cannot be reached by routine FBS, fluoroscopy guided transbronchial lung biopsy can increase the accuracy of the diagnosis. Recently, other fusion techniques, including EBUS and navigation bronchoscopy, have been developed and used to improve diagnostic yield.

\section{EBUS-TBNA}

EBUS-TBNA, which was introduced to identify mediastinal $\mathrm{L} / \mathrm{N}$ metastasis of lung cancer, is now widely used 
not only for the examination of $\mathrm{L} / \mathrm{N}$ but also for the identification and biopsy of central lesions that cannot be reached by FBS. The EBUS-TBNA needle is typically inserted through the wall of the trachea or main bronchus into the mass or the lymph node. During this procedure, the position of the target lesion is confirmed based on real-time ultrasound images [15]. The highest mediastinal, upper paratracheal, lower paratracheal, subcarinal, hilar, and interlobar L/Ns can be assessed using this methodology with low complication rate [16]. However, the para-aortic, aortopulmonary window or subaortic, paraesophageal, and pulmonary ligament $\mathrm{L} / \mathrm{Ns}$ are not accessible through this technique. The diagnostic yield for EBUS-TBNA is high with a sensitivity of $90 \%$ and a negative predictive value of $93 \%$ [17]. In patients with negative results in a standard FBS, EBUS-TBNA was able to confirm primary central lung cancer with a sensitivity of $77 \%$ [18].

\section{EBUS using a guide sheath}

Using a radial EBUS probe, it is possible to detect peripheral lung lesions surrounding the tip of the probe. The image of radial-type EBUS can be obtained using a guide sheath (GS). Biopsy forceps and bronchial brushes can be placed using GS. This method is superior to FBS or EBUS accessing small peripheral lung lesions [14]. The accessible airways closest to the lesion are marked as targets. The radial probe is then inserted into the target lesion through the bronchoscope. After retraction of the radial probe, forceps or brushes can be placed to further biopsy target lesions. Until recently, the diagnostic yield and safety of EBUS-GS have not been fully evaluated. Most studies investigating this issue were based on single center case reports or were meta-analyses. However, a larger number of studies have now shown the good diagnostic yield of EBUSGS and confirmed that it is a well-tolerated procedure $[14,19,20]$.

\section{Navigation bronchoscopy}

Navigation bronchoscopy is generally adopted for small peripheral lung lesions to increase diagnostic accuracy. This technique includes three stages. In the first stage, or the planning stage, a CT scan is reconstructed and a virtual road map to the target is created. In the second stage, or registration stage, an electromagnetic field is created around the body using sensors to overlap the virtual and the actual body. The last stage is the navigation stage where the above information is used for navigation to guide the probe to the target site [21]. The diagnostic yield of this method has been found to range from $33 \%$ to $97 \%$ [22]. Incidence of pneumothorax is the most frequent complication for this method and occurs in approximately $3 \%$ of all cases [23]. The technician's expertise; the volume, location, and characteristics of the lung lesions; concurrent EBUS; and the use of catheter aspiration are important factors that can influence the diagnostic yield of this method.

\section{Transthoracic needle aspiration biopsy with CT guidance}

CT-needle aspiration biopsy (NAB) is one of the most commonly used tools to secure lung tissue, and its diagnostic yield is dependent on the size of the target lung lesion. Typically, lung nodules over 1 to $2 \mathrm{~cm}$ in size are good candidates for CT-NAB. Previous studies have shown that the diagnostic yield for CT-NAB ranged from $77 \%$ to $94 \%$. It is an invasive procedure and can provide an alternative to surgery for the confirmation of lung cancer diagnosis. However, this technique is associated with a risk of complications. A recent study revealed that the associated rates of pneumothorax and bleeding were $20 \%$ and $3 \%$, respectively [24]. Another study showed that pneumothorax requiring intervention occurred in $4.3 \%$ of patients, and that major complications developed in $4.4 \%$ of those patients [25]. Larger needle diameters, increased transverse lung parenchyma, and smaller lesion sizes are risk factors for the development of major complications in this procedure [25]. Contraindications to the use of CT-NAB are bleeding diathesis, low platelet count, prolonged prothrombin time or partial thromboplastin time and international normalized ratio, pulmonary hypertension, emphysematous disease and chronic obstructive pulmonary disease, large bullae in the biopsy path, and patients with challenges such as intractable cough or those using mechanical ventilation. The ability of patients to hold their breath and maintain their position is important for this procedure. A careful selection of patients is needed in order to attain better yields and reduce complication rates. Recently, improvements have been made to this 
Table 3. Commonly used molecular markers for lung cancer in Korea

\begin{tabular}{|c|c|c|c|c|}
\hline Molecular marker & Prevalence (in Korea) & Most common mutation & Molecular method & Available medicine \\
\hline EGFR mutation & $\begin{array}{l}20 \%-56 \% \text { in } \\
\text { adenocarcinoma }\end{array}$ & E19del, L858R & $\begin{array}{l}\text { RT-PCR, Sanger } \\
\text { sequencing, NGS }\end{array}$ & $\begin{array}{l}\text { Osimertinib, gefitinib, } \\
\text { afatinib, dacomitinib } \\
\text { erotinib }\end{array}$ \\
\hline$A L K$ & $3 \%-5 \%$ in NSCLC & EML4-ALK fusion & $\begin{array}{l}\text { FDA-approved IHC, } \\
\text { FISH, NGS }\end{array}$ & $\begin{array}{l}\text { Alectinib, crizotinib, } \\
\text { ceritinib, brigatinib }\end{array}$ \\
\hline $\operatorname{ROS}_{1}$ & $\begin{array}{l}2 \%-3 \% \text { in } \\
\text { adenocarcinoma }\end{array}$ & $\begin{array}{l}C D_{74}, S_{2 L} C_{34} A 2 \\
\text { CCDC6, FIG }\end{array}$ & $\begin{array}{l}\text { FDA-approved IHC, } \\
\text { FISH, NGS }\end{array}$ & Crizotinib \\
\hline BRAF & $1.8 \%$ in adenocarcinoma & V6ooE & $\begin{array}{l}\text { RT-PCR, Sanger } \\
\text { sequencing, NGS }\end{array}$ & Dabrafenib, trametinib \\
\hline $\begin{array}{l}\mathrm{PD}-1 / \mathrm{PD}-\mathrm{L} 1 \\
\text { expression }(\geq 1 \%)\end{array}$ & $42 \%$ & & FDA-approved IHC & $\begin{array}{l}\text { Nivolumab, } \\
\text { pembrolizumab, } \\
\text { atezolizumab, } \\
\text { durvalumab }\end{array}$ \\
\hline
\end{tabular}

RT-PCR, reverse transcription polymerase chain reaction; NGS, next generation sequencing; NSCLC, non-small cell lung cancer; FDA, food and drug administration; IHC, immunohistochemistry; FISH, fluorescent in situ hybridization.

technique including the addition of laser guidance to improve its accuracy and reduce the risk of complications [26].

\section{Gun biopsy}

Various types of needles are available for CT-NAB and the choice of needle is dependent on the size, location, and characteristics of the target lesions, and the technician's expertise and preference. There are mainly three types of needles used: aspiration needles, cutting needles, and automated core biopsy needles. Aspiration needles are thin-walled and flexible, and cellular material for microscopic or cytological diagnosis can be obtained using these needles [27]. Cutting needles, which are modified aspiration needles with a side cutting tip, are used to obtain histologic specimens. Lastly, core biopsies can be performed using a biopsy gun without causing crushing injuries. Specimens obtained from core biopsies increase the rate of definite benign disease and allow for the characterization of different cell types. The diagnostic yield of core biopsy is superior to that of CT-NAB particularly in benign disease and specimen obtained from core biopsy is more suitable for immunochemical and genetic variation test compared to that from fine needle aspiration. On the other hand, it has an increased associated risk of complications. The reported overall complication rate and major complication rate are $38 \%$ and $6 \%$, respectively, for this technique. In a previous study, pneumothorax and pulmonary hemorrhage developed in $25 \%$ and $18 \%$ of patients, respectively [25]. The choice of biopsy needle for transthoracic needle biopsies should be considered on a case-by-case basis for the improvement of the diagnostic yield, purpose of biopsy, and the reduction in the rate of complications.

\section{LABORATORY TESTS}

Genomic alterations are an important cause of cancer initiation, growth, and progression. Various technological advancements in cancer genomic analysis platforms have made possible the identification of genomic alterations that can impact the therapeutic response in lung cancer. Therefore, genetics/genomics research is actively being conducted in the lung cancer field, and factors such as EGFR, ALK, and ROS1 have been identified and are currently being used as targets for lung cancer treatment. In addition, data regarding mutations in genes such as BRAF, VEGF, KRAS, RET, and MET are also being used for cancer treatment, in addition to immunological markers such as programmed cell death (PD)-1 and PD ligand 1 (PD-L1) (Table 3) [28].

\section{Polymerase chain reaction based tests}

Polymerase chain reaction (PCR) is a revolutionary 
method invented in 1983 that allows for large amounts of DNA to be amplified in vitro using two primers. PCRbased assays have been continually amended to make it easier to find driver mutations such as EGFR in the medical practice. Dideoxynucleotide sequencing, developed by Sanger et al. [29], of PCR-amplified DNA is the standard method for the detection of genomic mutations; however, it shows suboptimal sensitivity, is labor- intensive, and has long turnover times. Other modified methods, such as PCR-single-strand conformation polymorphism, TaqMan PCR, Cycleave PCR, PCR-restriction length polymorphism, peptide nucleic acid-locked nucleic acid PCR clamp, and mutant-enriched PCR, have been developed and showed improved sensitivity when compared to conventional PCR methods. Kim et al. [30] compared the PNA-mediated PCR clamping method and the direct-sequencing method using the tissues of 112 lung cancer patients. They demonstrated that mutants were identified in 45 samples using the PNA-mediated clamping method, 10-fold more than that when using direct-sequencing, and indicated that this method can be useful for detecting driver mutations [31]. Now, PNA-mediated clamping method is one of the most commonly used methods to detect driver mutations in cancer tissue specimen in Korea.

\section{Next generation sequencing based tests}

Next generation sequencing (NGS) is a methodology that quickly decodes a large amount of genome information by breaking down a genome into numerous fragments, reading each fragment simultaneously, and finally combining the data obtained using bioinformatics techniques [32]. Hybrid capture sequencing is used when whole genome, whole exome, or large targeted panels are assessed, whereas amplicon sequencing is used when in-depth reading is required and assay sensitivity is being evaluated. Targeted NGS panels have been validated in several previous studies. Targeted NGS panels, including those for EGFR, KRAS, BRAF, and MET, are widely used in lung cancer [33]. Wider analyses can take up to a week to complete. From these large NGS datasets, in addition to EGFR, KRAS, and BRAF mutations, $36 \%$ of lung cancer patients can be found to harbor other potential driver mutations (FGFR, ERBB2, AKT, and MAP2K1, STK11) [34-36]. Many NGS panels that include more diverse genes, tumor mutational burden, microsatellite instability status detection, and fusions are currently under development and will provide more detailed information on lung cancer genetics. Since 2017, the NGS technology base genetic panel test has been designated as an object for national health insurance benefits in Korean lung cancer patients. When applying NGS in lung cancer in Korea and claiming insurance, the essential requirements of the genetic panel should include following 14 genes; HER2, EGFR, ALK, KRAS, NRAS, BRAF, BRCA1, BRCA2, KIT, PDGFRA, IDH1, IDH2, MYC, MYCN [37]. However, NGS can yield false negatives or positives, and therefore, additional tests such as fluorescence in situ hybridization or immunohistochemistry (IHC) for protein overexpression may improve the patients' diagnosis.

\section{Real-time PCR}

There are two types of commonly used real-time PCR methods: real-time PCR using a TaqMan probe and real-time PCR using SYBR Green. Although tissue biopsies are the gold standard for detecting driver mutations, they are invasive and sometimes challenging to obtain due to the patient's condition and tumor location or size. Contrary to tissue biopsy, a liquid biopsy from plasma, pleural effusion, or bronchoalveolar lavage fluid is typically less invasive [38]. Previous studies have shown promising data using liquid biopsies and real-time PCR [39]. Shin et al. [39] reported a 100\% sensitivity and concordance rate of $98.7 \%$ with real-time PCR for EGFR using pleural effusions when compared to Sanger sequencing and PNA-mediated PCR clamping.

\section{Transcriptome analysis}

In transcriptome analysis, analysis is performed using microarray, an RNA sequencing method that separates mRNA, converts it into cDNA, and analyses its sequence using NGS. Whole transcriptome profiles can easily be obtained from Gene Expression Omnibus (GEO) databases. Lim et al. [40] integrated robust datasets into the bioinformatics pipeline using statistical methods and presented normalized datasets in lung cancer. Bang et al. [41] conducted transcriptome analyses for 10 NSCLC patients and reported that genes related to the cell cycle were highly upregulated in lung cancer. They validated these results using public data available in GEO and 
The Cancer Genome Atlas (TCGA). MFAP4 and AGER genes were significantly downregulated and the SPP1 gene was upregulated in NSCLC, and these genes were significantly associated with poorer prognoses.

Transcriptome alterations associated with lung cancer can easily be identified using tissue samples for early detection, screening, and prevention of lung cancer [42]. Several studies have reported the effects of smoking on the transcriptome of thoracic airway epithelium and showed that genes related to oxidative stress, apoptosis, profibrosis, mucin production, anti-oxidants, anti-proteases, and immune-related processes were enriched. Silvestri et al. [43] prospectively evaluated a bronchial-airway gene-expression classifier to improve the diagnostic performance of FBS in 639 patients with suspected lung cancer and found that it improved the sensitivity of lung cancer diagnosis.

\section{IHC tests}

IHC is used in the differential diagnosis of adenocarcinoma and squamous carcinoma (SqCC); neuroendocrine marker identification; driver mutation assessment, including that for EGFR/ALK/ROS 1 and PD-L1/PD-1 expression; and the differential diagnosis of lung cancer and mesothelioma [7]. Thyroid transcription factor-1 and napsin $\mathrm{A}$ are used as adenocarcinoma markers, and p40, CK5/6, and TP63 can be used as SqCC markers [44]. According to World Health Organization classification, assessment of both neuroendocrine morphology and immunohistochemical expression (chromogranin A, synaptophysin, or $\mathrm{CD}_{5} 6$ ) is required for the diagnosis of large cell neuroendocrine carcinoma. For the detection of driver mutations, the U.S. Food and Drug Adminstration (FDA)-approved ALK D5F antibody is used for ALK-rearranged NSCLC as a companion diagnostic tool [45]. However, IHC analysis is not used in EGFR mutation screening due to its low sensitivity. IHC methods for PD-L1/PD-1 varies between providers. The U.S. FDA approved the $22 \mathrm{C}_{3}$ antibody for pembrolizumab, the 28-8 antibody for nivolumab, and SP142 for atezolizumab [46]. Many studies have reported that PD-L1/PD-1 levels correlate to treatment response and prognosis; however, further research will be needed to fully understand these pathways in cancer [47]. Calretinin, BAP1, podoplanin, $\mathrm{CK}_{5}, \mathrm{CK}_{5} / 6$, and WT1 can be potentially used for the diagnosis of mesothelioma [48].

\section{FUTURE DIAGNOSIS FOR LUNG CANCER}

With the continuous development of new therapeutic modalities for lung cancer, the demand for re-biopsy has grown concurrently along with the increase in survival rates. Companion diagnostics, including immunochemical, genetic, and transcriptome analyses, for application of lung cancer therapeutic agent are associated with an increasing demand for a large amount of fresh tissue. However, it is often not feasible to perform additional invasive tests to obtain fresh specimens, especially in patients who have experienced relapses during long-term anti-cancer treatment. Therefore, in addition to the development of safe and convenient techniques for obtaining fresh tissues, sensitive laboratory diagnostic methods that can obtain accurate results with a small amount of specimen should be developed. In this regard, liquid biopsy using blood has drawn much attention, but is only useful in patients with an advanced disease stage and has limitations in those with small tumor burden [49]. The utility of circulating tumor cells (CTCs) and circulating tumor DNA (ctDNA) in liquid biopsies has been extensively evaluated. Research on CTCs is waning little by little due to the lack of biomarkers that can accurately identify and secure CTCs except epithelial cell adhesion molecule (EpCAM) and to additional requirement for high efficiency platforms that enrich and enumerate CTCs [50]. On the other hand, the clinical usefulness of ctDNA is gradually increasing due to the development of ctDNA preservation and detection technology.

Also, there have been advances not only in bronchoscopy techniques itself but also in adjuvant therapy administered before and after the procedures. EBUS is now standardized diagnostic tool for lung cancer diagnosis and mediastinal L/N staging and EBUS-GS have been introduced at a number of medical institutions in Korea. EBUS-GS has the advantage of being able to reach peripheral small lung lesions and is useful for obtaining tissues. Diagnostic yield of EBUS-GS brushing cytology alone is not still satisfactory, requiring development of technologies that can increase the diagnostic yield [9]. In contrast, the introduction of navigation bronchoscopy is relatively slow, possibly because it serves the similar purpose as EBUS-GS in examining small peripheral lesions but is cost-inten- 
sive and requires additional facilities. The lungs are mostly composed of air-filled loose tissue that makes exact examination of the entire lung structure difficult using MRI or ultrasonography alone. However, novel diagnostic tools are being developed by overcoming the shortcomings of different methods and combining their advantages. One example is EBUS, a combination of ultrasound and optical bronchoscopy, employing navigation of the bronchoscope based on CT image analysis.

\section{CONCLUSIONS}

Increasing interest in health, regular check-ups, and development of new treatment modalities has led to increasing demands for procurement of tissue for routine diagnosis but also companion diagnostics. In this review, we discussed the diagnostic methods for lung cancer that are widely used in current medical practice, and we described their advantages and limitations including complementary relation between different diagnostic tools with the aim of contributing to the appropriate selection and application of these techniques in lung cancer patients.

\section{Conflict of interest}

No potential conflict of interest relevant to this article was reported.

\section{Acknowledgments}

This work was supported by the National Research Foundation of Korea (grant number NRF-2017R1A2B4009017) awarded to Yoon Soo Chang.

\section{REFERENCES}

1. Ministry of Health and Welfare, Korea Central Cancer Registry, National Cancer Center. Annual report of cancer statistics in Korea in 2016 [Internet]. Goyang (KR): National Cancer Center; 2016 [cited 2020 Feb 24]. Available from: https://ncc.re.kr/main.ncc?uri=english/subo4_Statistics.

2. Kim YC, Won YJ. The development of the Korean lung cancer registry (KALC-R). Tuberc Respir Dis (Seoul) 2019;82:91-93.
3. Park CK, Kim SJ. Trends and updated statistics of lung cancer in Korea. Tuberc Respir Dis (Seoul) 2019;82:175-177.

4. Korean Statistical Information Service. Causes of death statistics in 2018 [Internet]. Daejeon (KR): KOSIS; 2018 [cited 2020 Feb 24]. Available from: http://kosis.kr.

5. Yeo CD, Lee MK, Lee $\mathrm{SH}$, et al. Indicators and qualitative assessment of lung cancer management by Health Insurance Review and Assessment Service (HIRA) of Korea in 2015. Tuberc Respir Dis (Seoul) 2018;81:19-28.

6. Gucalp R, Dutcher JP. Oncologic Emergencies. In: Jameson JL, Kasper DL, Longo DL, Fauci AS, Hauser SL, Loscalzo J, eds. Harrison's Principles of Internal Medicine. 2oth ed. Vol. 1. New York (NY): McGraw Hill Educations, 2018:511-512.

7. Horn L, Lovely CM. Neoplasms of the lung. In: Jameson JL, Kasper DL, Longo DL, Fauci AS, Hauser SL, Loscalzo J, eds. Harrison's Principles of Internal Medicine. 2oth ed. Vol. 1. New York (NY): McGraw Hill Education, 2018:537555 .

8. Jameson JL, Longo DL. Paraneoplastic syndromes: endocrinologic/hematologic. In: Jameson JL, Kasper DL, Longo DL, Fauci AS, Hauser SL, Loscalzo J, eds. Harrison's Principles of Internal Medicine. 2oth ed. Vol. 1. New York (NY): McGraw Hill Education, 2018:662-668.

9. National Lung Screening Trial Research Team, Aberle DR, Adams AM, et al. Reduced lung-cancer mortality with low-dose computed tomographic screening. N Engl J Med 2011;365:395-409.

10. Lee J, Kim YK, Seo YY, et al. Clinical characteristics of false-positive lymph node on chest CT or PET-CT confirmed by endobronchial ultrasound-guided transbronchial needle aspiration in lung cancer. Tuberc Respir Dis (Seoul) 2018;81:339-346.

11. Goldberg SB, Contessa JN, Omay SB, Chiang V. Lung cancer brain metastases. Cancer J 2015;21:398-403.

12. Song JU, Song J, Lee KJ, et al. Are there any additional benefits to performing positron emission tomography/ computed tomography scans and brain magnetic resonance imaging on patients with ground-glass nodules prior to surgery? Tuberc Respir Dis (Seoul) 2017;80:368376.

13. Ettinger DS, Wood DE, Aggarwal C, et al. NCCN guidelines insights: non-small cell lung cancer, version 1.2020 . J Natl Compr Canc Netw 2019;17:1464-1472.

14. Moon SM, Choe J, Jeong BH, et al. Diagnostic performance of radial probe endobronchial ultrasound without 
a guide-sheath and the feasibility of molecular analysis. Tuberc Respir Dis (Seoul) 2019;82:319-327.

15. Sampsonas F, Kakoullis L, Lykouras D, Karkoulias K, Spiropoulos K. EBUS: faster, cheaper and most effective in lung cancer staging. Int J Clin Pract 2018;72.

16. Kim SY, Lee JW, Park YS, et al. Incidence of fever following endobronchial ultrasound-guided transbronchial needle aspiration. Tuberc Respir Dis (Seoul) 2017;80:45-51.

17. Dong X, Qiu X, Liu Q, Jia J. Endobronchial ultrasound-guided transbronchial needle aspiration in the mediastinal staging of non-small cell lung cancer: a meta-analysis. Ann Thorac Surg 2013;96:1502-1507.

18. Tournoy KG, Rintoul RC, van Meerbeeck JP, et al. EBUS-TBNA for the diagnosis of central parenchymal lung lesions not visible at routine bronchoscopy. Lung Cancer 2009;63:45-49.

19. Gupta A, Youness H, Dhillon SS, Harris K. The value of using radial endobronchial ultrasound to guide transbronchial lung cryobiopsy. J Thorac Dis 2019;11:329-334.

20. Kim EJ, Kim KC. Utility of radial probe endobronchial ultrasound-guided transbronchial lung biopsy in diffuse lung lesions. Tuberc Respir Dis (Seoul) 2019;82:201-210.

21. Mehta AC, Hood KL, Schwarz Y, Solomon SB. The evolutional history of electromagnetic navigation bronchoscopy: state of the art. Chest 2018;154:935-947.

22. Yarmus LB, Arias S, Feller-Kopman D, et al. Electromagnetic navigation transthoracic needle aspiration for the diagnosis of pulmonary nodules: a safety and feasibility pilot study. J Thorac Dis 2016;8:186-194.

23. Gex G, Pralong JA, Combescure C, Seijo L, Rochat T, Soccal PM. Diagnostic yield and safety of electromagnetic navigation bronchoscopy for lung nodules: a systematic review and meta-analysis. Respiration 2014;87:165-176.

24. DiBardino DM, Yarmus LB, Semaan RW. Transthoracic needle biopsy of the lung. J Thorac Dis 2015;7:S304-S316.

25. Heerink WJ, de Bock GH, de Jonge GJ, Groen HJ, Vliegenthart R, Oudkerk M. Complication rates of CT-guided transthoracic lung biopsy: meta-analysis. Eur Radiol 2017;27:138-148.

26. Jeon MC, Kim JO, Jung SS, et al. CT-guided percutaneous transthoracic needle biopsy using the additional laser guidance system by a pulmonologist with 2 years of experience in CT-guided percutaneous transthoracic needle biopsy. Tuberc Respir Dis (Seoul) 2018;81:330-338.

27. Birchard KR. Transthoracic needle biopsy. Semin Intervent Radiol 2011;28:87-97.
28. El-Telbany A, Ma PC. Cancer genes in lung cancer: racial disparities: are there any? Genes Cancer 2012;3:467-480.

29. Sanger F, Nicklen S, Coulson AR. DNA sequencing with chain-terminating inhibitors. Proc Natl Acad Sci U S A 1977;74:5463-5467.

30. Kim HJ, Lee KY, Kim YC, et al. Detection and comparison of peptide nucleic acid-mediated real-time polymerase chain reaction clamping and direct gene sequencing for epidermal growth factor receptor mutations in patients with non-small cell lung cancer. Lung Cancer 2012;75:321325 .

31. Lee HJ, Xu X, Kim H, et al. Comparison of direct sequencing, PNA clamping-real time polymerase chain reaction, and pyrosequencing methods for the detection of EGFR mutations in non-small cell lung carcinoma and the correlation with clinical responses to EGFR tyrosine kinase inhibitor treatment. Korean J Pathol 2013;47:52-60.

32. Park CK, Oh IJ, Kim YC. What is currently the best for adenocarcinoma without driver mutation? Tuberc Respir Dis (Seoul) 2018;81:258-259.

33. Garinet S, Laurent-Puig P, Blons H, Oudart JB. Current and future molecular testing in NSCLC, what can we expect from new sequencing technologies? J Clin Med 2018;7:144.

34. Bennett NC, Farah CS. Next-generation sequencing in clinical oncology: next steps towards clinical validation. Cancers (Basel) 2014;6:2296-2312.

35. Sanchez-Cespedes M, Parrella P, Esteller M, et al. Inactivation of $\mathrm{LKB} / \mathrm{STK} 11$ is a common event in adenocarcinomas of the lung. Cancer Res 2002;62:3659-3662.

36. Fang R, Zheng C, Sun $Y$, et al. Integrative genomic analysis reveals a high frequency of $\mathrm{LKB} 1$ genetic alteration in Chinese lung adenocarcinomas. J Thorac Oncol 2014;9:254-258.

37. South Korea Ministry of Health and Welfare. Ministry of Health and Welfare. Notice 2017-19. Partial revision to details on criteria and method of application for medical care benefits [Internet]. Sejong (KR): MOHW, 2017 [cited $2020 \mathrm{Feb} 25$ ]. Available from: http://www.mohw.go.kr/react/jb/sjbo406vw.jsp.

38. Wu Z, Yang Z, Dai Y, Zhu Q, Chen LA. Update on liquid biopsy in clinical management of non-small cell lung cancer. Onco Targets Ther 2019;12:5097-5109.

39. Shin S, Kim J, Kim Y, Cho SM, Lee KA. Assessment of real-time PCR method for detection of EGFR mutation using both supernatant and cell pellet of malignant pleu- 
ral effusion samples from non-small-cell lung cancer patients. Clin Chem Lab Med 2017;55:1962-1969.

40. Lim SB, Tan SJ, Lim WT, Lim CT. A merged lung cancer transcriptome dataset for clinical predictive modeling. Sci Data 2018;5:180136.

41. Bang MS, Kang K, Lee JJ, et al. Transcriptome analysis of non-small cell lung cancer and genetically matched adjacent normal tissues identifies novel prognostic marker genes. Genes Genom 2017;39:277-284.

42. Gesthalter YB, Vick J, Steiling K, Spira A. Translating the transcriptome into tools for the early detection and prevention of lung cancer. Thorax 2015;70:476-481.

43. Silvestri GA, Vachani A, Whitney D, et al. A bronchial genomic classifier for the diagnostic evaluation of lung cancer. N Engl J Med 2015;373:243-251.

44. Inamura K. Lung cancer: understanding its molecular pathology and the 2015 WHO classification. Front Oncol 2017;7:193.

45. Thorne-Nuzzo T, Williams C, Catallini A, et al. A sensitive ALK immunohistochemistry companion diagnostic test identifies patients eligible for treatment with Crizotinib.
J Thorac Oncol 2017;12:804-813.

46. Jung CY, Antonia SJ. Tumor immunology and immune checkpoint inhibitors in non-small cell lung cancer. Tuberc Respir Dis (Seoul) 2018;81:29-41.

47. Park HY, Oh IJ, Kho BG, et al. Clinical characteristics of Korean patients with lung cancer who have programmed death-ligand 1 expression. Tuberc Respir Dis (Seoul) 2019;82:227-233.

48. Husain AN, Colby TV, Ordonez NG, et al. Guidelines for pathologic diagnosis of malignant mesothelioma 2017 update of the consensus statement from the international mesothelioma interest group. Arch Pathol Lab Med 2018;142:89-108.

49. Kim T, Kim EY, Lee SH, Kwon DS, Kim A, Chang YS. Presence of mEGFR ctDNA predicts a poor clinical outcome in lung adenocarcinoma. Thorac Cancer 2019;10:22672273.

50. Kang BJ, Ra SW, Lee K, et al. Circulating tumor cell number is associated with primary tumor volume in patients with lung adenocarcinoma. Tuberc Respir Dis (Seoul) 2020;83:61-70. 